\title{
KAJIAN KELAYAKAN USAHATANI KELAPA SAWIT DI KECAMATAN TUNGKAL JAYA KABUPATEN MUSI BANYUASIN (Studi Kasus Anggota Kelompok Tani di Koperasi Unit Desa Bersama Makmur)
}

\author{
Rogayah
}

Fakultas Pertnian Universitas Batanghari Jambi

Email : rogayah_gayah@yahoo.com

\begin{abstract}
This research was done in the village of Srimulyo sub-district of 1957 Jaya because internally and externally the village can still dikembangka and supported by the development of the downstream industry. The method used is the method of measurement, with the aim of examining leyakan of farming. The number of samples that are in the RTP 56 farmer groups in cooperative Villages Prosperous, by means of simple random sampling. Judging from the results of the eligibility tests done (BCR $>1$ ) then it can be inferred to be forwarded is worthy of farming because it is profitable for farmers.
\end{abstract}

Keywords: revenue, palm, merchantibility

\begin{abstract}
Abstrak
Penelitian ini di lakukan di Desa Srimulyo Kecamatan Tungkal Jaya karena secara internal dan eksternal desa ini masih bisa dikembangka dan didukung oleh perkembangan industry hilir. Metode yang digunakan adalah metode survai, dengan tujuan mengkaji leyakan usahatani. Jumlah sampel 56 RTP yang berada dalam kelompok tani di Koperasi Desa Bersama Makmur,dengan cara simple random sampling.Dilihat dari hasil uji kelayakan yang dilakukan (BCR > 1 ) maka dapat disimpulkan usahatani ini layak untuk diteruskan karena menguntungkan bagi petani.

Kata kunci: Pendapatan, kelapa sawit, kelayakan usaha
\end{abstract}

\section{PENDAHULUAN}

Secara umum dapat dikatakan bahwa pengembangan agribisnis kelapa sawit masih mempunyai peluang yang cukup besar, ditinjau dari prospek harga,ekspor dan pengembangan produk. Pengembangan agribisnis kelapa sawit secara internal didukung potensi kesesuaian dan ketersediaan lahan,produktivitas yang masih dapat meningkat dan semakin berkembangnya industri hilir yang merupakan pengolah hasil kelapa sawit.

Kabupaten Musi Banyuasin merupakan salah satu kabupaten di Sumatera Selatan yang mempunyai peluang dan potensi pengembangan usaha perkebunan hal ini terlihat dari perkembangan perkebunan kelapa sawit yang dari tahun ke tahun mengalami peningkatan.

Kecamatan Banyu Lincir merupakan salah satu Kecamatan yang berada di Kabupaten Musi Banyuasin yang dominan masyarakatnya mengusahakan tanaman kelapa sawit sebagai mata pencarian pokok (Musi Banyu Asin Dalam Angka, 2011). 
Desa Srimulyo merupakan salah satu desa yang terdapat dalam wilayah kecamatan banyu lincir dengan luas wilayah $15 \mathrm{~km}^{2}$,jumlah penduduk sebanyak 2287 jiwa yang terdiri dari 634 kepala keluarga (KK) dengan jumlah petani kelapa sawit sebanyak 376 kepala keluarga (KK) dan terbagi dalam 16 kelompok (KUD Bersama Makmur,2011)

Usahatani kelapa sawit yang ada di Desa Srimulyo adalah perkebunan rakyat dimana lahan yang diusahakan merupakan lahan pemberian pemerintah melalui transmigrasi dan dikelola oleh PT Hindoli, kemudian dikelola oleh masyarakat yang bernaung dibawah pengawasan KUD dan PT Hindoli

Permasalahan dalam penelitian ini adalah:

Apakah usahatani yang di jalankan petani kelapa sawit sudah memberikan pendapatan yang layak.

Penelitian ini bertujuan untuk mengkaji kelayakan pendapatan yang diperoleh petani.

\section{METODOLOGI PENELITIAN}

Penelitian dilaksanakan di desa Srimulyo KecamatanTungkal Jaya Kabupaten Banyuasin Sumatra Selatan.dipilihnya lokasi penelitian Koperasi Unit Desa Bersama Makmur secara sengaja karena KUD ini merupakan KUD terbaik bidang administrasi yang bergerak dalam bidang perkebunan kelapa sawit.

Data primer diperoleh dari hasil wawancara langsung dengan petani sampel dan data sekunder diperoleh dari laporan hasil penelitian dan instansi terkait yang berhubungan dengan penelitian ini,sedangkan metode yang digunakan dalam pengumpulan data digunakan metode survei

Populasi petani sawit di KUD Bersama Makmur sebanyak 376 kepala keluarga (rumah tangga petani/ RTP) yang terdiri dari 16 kelompok, diambil $15 \%$ dari jumlah populasi sehingga diperoleh sampel sebanyak 56 rumah tangga petani (RTP),sampel dipilih dengan menggunakan metode simple ramdom sampling

Sesuai dengan tujuan penelitian data yang diperoleh di tabulasi kemudian di analisis untuk menghitung pendapatan per bulan menggunakan rumus $\mathrm{Pd}=\mathrm{TR}-\mathrm{TC}$, yaitu total revenue (jumlah produksi $\mathrm{x}$ harga/satuan) di kurangi dengan total cost (Soekartawi, 2006) sedangkan untuk mengetahui kelayakan usaha digunakan rumus Benefit Cost of Ratio (BCR), yaitu merupakan perbandingan antara pendapatan bersih dengan biaya yang dikeluarkan (penbapatan : total biaya), dengan kaidah keputusan bila BCR >1 usahatani tersebut layak untuk diteruskan karena menguntungkan (Departemen Pertanian,1997).

\section{HASIL PENELITIAN DAN PEMBAHASAN}

Rata-rata umur petani sampel adalah 46,6 tahun,hal ini menunjukkan bahwa petani berada pada golongan umur produktif sehingga masih memiliki kemampuan fisik yang baik untuk mengelola usahatani. Rata-rata pendidikan tamat SD/sederajat, tingkat pendidikan akan mempengaruhi cara berpikir untu menerima dan mencoba hal-hal baru.Rata-rata jumlah anggota keluarga 4 orang,jumlah anggota keluarga merupakan beban bagi petani dan akan mempengaruhi pilihan keputusan yang akan diambil. 
Biaya produksi usahatani merupakan korbanan yang dikeluarkan oleh petani sampel dalam mengelola usahataninya, biaya terdiri dari biaya tetap dan biaya variable. Biaya tetap adalah biaya yang tidak habis dipakai dalam satu kali proses produksi yang dihitung penyusutannya dengan menggunakan rumus $\mathrm{BPA}=($ harga alat $\mathrm{x}$ jumlah - Nilai Sisa) : Umur Ekonomis dengan asumsi nilai sisa $=0$ (Sudarman dan Algifari, 2011), sedangkan biaya variable adalah biaya yang habis dipakai dalam satu kali proses produksi. Rata-rata biaya komponen biaya produksi petani sampel per Ha per bulan di desa Srimulyo sebagai berikut.

Tabel 1: Rata-rata Komponen Biaya Produksi Usahatani Kelapa Sawit Per Ha Per Bulan.

\begin{tabular}{clrc}
\hline No: & \multicolumn{1}{c}{ Jenis Biaya } & Jumlah Rp/Ha/Bulan & $\begin{array}{c}\text { Rata-rata } \\
\text { Rp/Ha/Bulan }\end{array}$ \\
\hline 1 & Biaya Tetap & 1.862 .290 & 33.255 \\
& -Biaya Penyusutan Alat & & \\
& & & \\
2 & Biaya Variabel & 16.432 .240 & 293.433 \\
& -Biaya Tenaga Pemanen & 26.600 .000 & 475.000 \\
& -Biaya Pupuk & 2.759 .500 & 49.277 \\
& -Biaya Herbisida & 1.493 .840 & 26.676 \\
& -Manajemen Fii & 15.535 .936 & 277.427 \\
& -Biaya Angkutan & 3.734 .600 & 66.689 \\
& -Biaya Tenaga Timbang & 1.176 .000 & 21.000 \\
& Muat & & \\
& -Infrastruktur & & 1.242 .757 \\
& & 69.594 .406 & \\
& & & \\
Total &
\end{tabular}

Dari tabel diatas terlihat bahwa komponen biaya rata-rata terbesar adalah biaya variable yaitu pada biaya penggunaan pupuk, biaya upah tenaga kerja panen dan diikuti oleh biaya angkutan serta biaya upah tenaga timbang muat dan rata-rat biaya sebesar Rp 1.242.757,-/Ha/Bulan

Harga tandan buah segar (TBS) adalah nilai dari produksi yang merupakan factor yang sangat berpengaruh langsung terhadap pendapatan yang diterima petani, harga tandan buah segar didaerah penelitian ditentukan oleh PT Hindolli dengan harga ratarata $\mathrm{Rp} 1,329,-/ \mathrm{Kg}$

Produksi usahatani kelapa sawit rata-rata sebanyak $2.668 \mathrm{Kg} / \mathrm{Ha} / \mathrm{Bulan}$, sehingga penerimaan rata-rata yang diperoleh petani adalah sebesar $\mathrm{Rp} 3.545 .772$,/Ha/Bulan,dengan demikian pendapatan adalah sebesar Rp 2.303.015,-/Ha/Bulan.

Sedangkan untuk melihat kelayakan usaha tersebut dipergunakan uji kelayakan Benefit Cost of Ratio (BCR),sehingga diperoleh BCR besar dari satu $(1,85)$ dengan kata lain usaha tersebut layak untuk di teruskan karena menguntungkan. 


\section{KESIMPULAN}

Berdasarkan hasil penelitian dapat disimpulkan bahwa:

1. Rata-rata biaya usahatani sebesar Rp 1.242.757,-/Ha/Bulan

2. Rata-rata Produksi kelapa sawit sebesar $2.668 \mathrm{Kg} / \mathrm{Ha} / \mathrm{Bulan}$

3. Rata-rata harga buah kelapa sawit $\mathrm{Rp} 1,329,-/ \mathrm{Kg}$

4. Rata-rata pendapatan yang diterima petani sebesar Rp 2.303.015,-/Ha/Bulan

5. Usahatani kelapa sawit ini layak untuk di teruskan karena menguntungkan bagi petani.

\section{DAFTAR PUSTAKA}

Anna Sinaga,Budiman dkk. 1997. Usahatani Kentang. Badan Penelitian Dan Pengembangan Pertanian.Lembang, Bandung

Bishop dan Tausaint, 1997. Pengantar Analisis Ekonomi Pertanian.Mutiara, Jakarta.

Hernanto.1996. Ilmu Usahatani.Penebar Swadaya. Jakarta

Yahya,S. 2007. Budidaya Kelapa Sawit (Elaeis Guineensis Jacq). Bahan Kuliah Tanaman Perkebunan Utama Jurusan Budidaya Pertanian. Fakultas Pertanian IPB. Bogor.

Soekartawi.1986. Ilmu Usahatani dan Penelitian Usaha Pengembangan Petani Kecil.Universitas Indonesia Press. Jakarta

Soehardjo dan Patong. 2002. Sendi-sendi Pokok Ilmu Usahatani.IPB. Bogor

Soekartawi. 1999. Prinsip Dasar Ekonomi Pertanian.Teori dan Aplikasinya. Rajawali Press. Jakarta.

Saekartawi. 2006. Analisis Usahatani. Jakarta: UI Press 